\title{
Effects of a change to more formative assessment among tertiary mathematics students
}

\author{
M. R. Freislich ${ }^{1} \quad$ A. Bowen-James ${ }^{2}$
}

(Received 25 February 2020; revised 1 July 2020)

\begin{abstract}
A change in teaching delivery at a large Australian university, from two semesters to three trimesters, was the occasion for using more formative assessment in a core first-year mathematics unit. This study compared evidence about learning outcomes for two cohorts in adjacent years. Cohort 1 was the last taught over a semester, and Cohort 2 the first taught over a trimester. There was no change in overall workload, and no change in the unit's total teaching hours, syllabus or materials. Assessments were changed for class tests during the teaching period by giving Cohort 2 access to unlimited practice and computer-assisted feedback on the questions in the test database, followed by doing the tests under examination conditions. For Cohort 2, a written assignment
\end{abstract}

Dor:10.21914/anziamj.v61i0.15166, C Austral. Mathematical Soc. 2020. Published 2020-09-02, as part of the Proceedings of the 14th Biennial Engineering Mathematics and Applications Conference. ISSN 1445-8810. (Print two pages per sheet of paper.) Copies of this article must not be made otherwise available on the internet; instead link directly to the DOI for this article. 
was also added, focused on giving a clear solution to a mathematics problem, and awareness of the need for appropriate evidence, both background and internal to the problem. Learning outcomes were compared using closely comparable tasks from the final examinations, and examining students' answers in the examination scripts. Outcomes were assessed by a method derived from the solo taxonomy, which afforded a common scale to measure the quality of learning outcomes observable in final examination scripts. Results on separate tasks, plus those for a composite score, favoured Cohort 2. The effect size for the composite score was $\mathbf{0 . 4 5 7}$. This indicates that the unlimited practice with computer feedback for class tests, and the writing assignment, were functioning as intended in promoting learning with understanding.

\section{Contents}

1 Introduction

2 Student learning

3 Support through formative assessment

C259

4 Comparing outcomes

C260

5 Method

C261

5.1 Sample...................... . C261

5.2 Data collected . . . . . . . . . . . . . . C262

5.3 Analysis and results. . . . . . . . . . . . . C263

5.3 .1 Comparison of means . . . . . . . . . . . C263

5.3.2 Distributions of scores . . . . . . . . . . . C265

6 Discussion

C266

A Appendix: Scoring examples

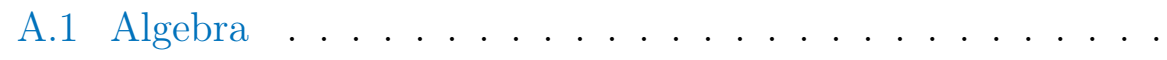




\section{Introduction}

The study described here deals with two cohorts of mathematics students, in adjacent years, in the same mathematics unit, which is the first unit in core programs for science and engineering students at a large Australian university. The two cohorts were, respectively, the last cohort taught over a semester, and the first cohort taught over a slightly shorter trimester, with the number of teaching hours, and overall student load unchanged. The basic delivery of the unit for both groups was through large lecture groups plus two tutorials a week, one face-to-face, and one online. In addition, between the two years there was no change in admission criteria, nor in the syllabus and teaching materials.

The change to trimesters was accompanied by a change in assessment methods. Cohort 1 was graded on two tests done in class, and a final examination, plus a small reward for working through the online tutorial tasks. For Cohort 2, the tests, final examination and the small contribution from online tutorials were retained, but the class tests were done online under examination conditions in computer laboratories, and an assignment was added, containing different tasks for different students to make blind copying impossible. The assignment focused on the clear and complete writing of solutions to a mathematical task, in the cause of increasing understanding of the process of problem solving, and the requirements of presenting evidence. The question bank used for the class tests was available to the students in advance, and all questions were among those present in the online tutorial program. Hence students had the opportunity for unlimited practice, as well as access to feedback on very similar questions. Both changes moved the assessment inside the teaching period towards being closer to formative than summative assessment. The final examination was designed to cover the whole syllabus, using tasks very similar to those in the examination for Cohort 1, but designed to be slightly more demanding. 
The present report describes a comparison between learning outcomes for the two cohorts, based on their performance in closely comparable tasks in the final examination. The background from research is described in Section 2.

\section{Student learning}

Research on student learning in recent decades, reviewed by Richardson [18], has emphasised the importance of approaches to studying founded on understanding material and seeing relationships among ideas. For mathematics students, assigned tasks usually set problems to be solved, on the grounds that understanding is fostered by doing mathematics, with attempts to produce solutions revealing gaps in understanding.

University mathematics students have chosen degree courses containing some mathematics, and have had reasonable success in secondary school mathematics, but many find the transition to university mathematics very difficult. Research findings from diverse backgrounds, such as the work done by McAldinen and Noyes [15] in Britain, Bengmark, Thunberg and Winberg [1] in Sweden, and Hillock and Khan [11] in Australia, emphasised the importance of the issue, and also note that the increasing diversity of students' previous educational experience may make transition more difficult for many of them. Nicholas et al. [16] found diversity of background very important among Australian students. In addition, Harris and Pampaka [9] found that British students had considerable difficulty resulting from rapid coverage of topics in university mathematics. Support that helps students to start the learning process by engaging in mathematical tasks should therefore be beneficial. The results of Rylands and Shearman [19] are compatible with such a claim. They found, in an Australian context, that engagement in mathematical activity offered in a learning support program was positively related to achievement. 


\section{Support through formative assessment}

Formative assessment is defined as assessment with feedback designed to inform understanding. In secondary mathematics, work in class and on assigned tasks can be used in this way. Face-to-face teaching can also afford scaffolding, originally defined by Wood, Bruner, and Ross [21] as a process of minimal intervention by an instructor that supports the student in a transition to a greater level of understanding.

In large university enrolment groups, limited resources preclude close one-toone guidance by instructors. It follows that giving support to students requires a different path. Holton and Clarke [13] proposed that mathematics students can achieve a transfer to self-scaffolding of learning by working through the solutions of a sequence of problems of increasing complexity. This still entails initial external guidance, involving help with handling the material, supplying feedback on work quality, and fostering students' persistence, so the limited resource problem is not directly addressed.

Some university programs use computer-assisted formative assessment, giving immediate feedback to students by informing them of errors. Programs that inform students when their results are wrong, but without presenting a correct solution, correspond to the minimal intervention required in providing scaffolding. Successful programs of this type have been implemented at university level. Jonsdottir, Bjornsdottir, and Stefansson [14] and Zetterqvist [22] found that design of material was of crucial importance, with successful results increasing over successive iterations of the design.

Carefully designed material, though, cannot have influence unless it is used, and incorporating learning resources into assessment gives a reward that promotes activity and persistence among students. Definitions of formative assessment permit giving marks, but preferably not too much of the final grade [15]. In the present study both cohorts completed specially designed weekly online tutorial tasks, with freedom about the time and the number of attempts, with completion contributing a small amount to the final mark. 
The changes in assessment for Cohort 2 provide two complementary tracks toward extended understanding. First, the assignment tested the writing of proofs, requiring clear statements, definition of terms, full explanations and formal language, as well as valid arguments. The students have time for revision, and can discuss points with their peers. The requirements of reflecting on evidence and clarity focus attention on the structure of an argument and the validity of each step. The mathematical tasks were the same for each student, but numerical data for each task were individualised.

The other change in assessment for Cohort 2 was the permitting of unlimited practice on the database containing the questions for the class tests, with students working online with computer-assisted feedback that identified wrong results. Clearly this affords an incentive to take action. It also incorporates a formative component into the summative assessment in the two tests. It also encourages questions to staff and discussion with peers, supplying a component similar to the original definition of scaffolding.

\section{Comparing outcomes}

The main gaps in the available evidence about outcomes of formative assessment are due to two features of the existing studies. In the first place, increases in formative assessment methods are often evaluated by surveying students about the perceived usefulness of the new assessments. In the results of Hodge, Richardson, and York [12], students reported that increased formative assessment had helped them to do more work. Seaton [20] found that students attached high value to doing assignments that were partially marked. Such work is useful for evaluating the design of tasks and feedback, but does not afford information about outcomes.

The second difficulty arises when studies evaluate formative assessment results as predictors of examination performance. For large groups, studies tend to focus on correlations between examination performance and either marks for online tasks or time spent on practice online, with computer-assisted feedback. 
Hannah, James, and Williams [8] found that among first year mathematics students, online results in formative assessment tasks correlated well with final examination marks, but this could be mainly a reflection of existing differences in ability and previous studies completed.

Direct comparisons of outcomes study either different assessments for different topics in a common subject, or comparisons between cohorts with control for initial comparability, in cases where formative assessment is introduced or increased for the second cohort. Gill and Greenow [7] used the first method, and found some evidence of higher achievement in topics where formative assessment was used. A cohort comparison was made by NúñezPeña, Bono, and Suárez-Pellicioni [17], in which the most important finding was that the negative correlation between mathematics anxiety and summative achievement, present in the first cohort, had disappeared among those offered the formative program.

It follows that there is very little direct evidence available about learning outcomes. In the present study a cohort comparison is used, for which, as indicated above, access to formative assessment differs in degree. Direct evaluation of observable learning outcomes was intended to fill some of the gaps in evidence described above.

\section{Method}

\subsection{Sample}

The samples were drawn from two cohorts of students in two successive years enrolled in the subject Mathematics 1A, which is the first core unit of mathematics for science and engineering students at a large Australian university. Simple random samples were drawn by taking every sixth name from the list of those who did the final examination. The sample from Cohort 1 consisted of 301 students, and that from Cohort 2 of 278. 
Table 1: Comparable tasks.

\begin{tabular}{ll|ll} 
Task & Topic & Task & Topic \\
\hline 1 & Roots of complex numbers & 5 & Solutions of linear equations \\
2 & Improper integrals & 6 & Implicit differentiation \\
3 & Techniques of integration & 7 & Mean Value Theorem \\
4 & Intersection of lines in $\mathbb{R}^{3}$ & 8 & Continuity for a split function
\end{tabular}

\subsection{Data collected}

Students' solutions to questions on the final examination were scored using the method described below. The two examination papers for the two cohorts contained eight almost identical tasks. The task material is listed in Table 1. Some detailed examples are in Appendix A.

For the eight chosen questions, to define levels of outcome, scores were given using a method derived from Australian work on learning outcomes developed by Biggs and Collis [2] forming the Structure of Observed Learning Outcomes (SOLO) Taxonomy. Their criteria were defined by the complexity, adequacy of coverage, and consistency of observable responses to set tasks. Biggs and Collis validated SOLO with examples of the work of pupils in upper primary and junior secondary schools. Applicability of the sOLO taxonomy was extended to mathematics performance at tertiary level by Chick, Watson and Collis [4]. The solo levels, as defined by Biggs and Collis [2], are in Table 2.

A classification based on the SOLO levels was developed and used by Freislich [5], Freislich [6], and Bowen-James [3] to produce a method of evaluating tertiary students' mathematics learning outcomes in a way that permits comparisons between groups doing similar tasks. In applying this classification, students' solutions to mathematical problems are placed into six levels, labelled from 0 to 5. In the current study, scores corresponding to the Extended abstract level are not defined because the data used did not offer scope for its detection. The first important criterion for evaluating written solutions is 


\begin{tabular}{|c|c|}
\hline Level & Definition \\
\hline Prestructural & Essentially no valid response \\
\hline Unistructural & $\begin{array}{l}\text { One aspect of the problem correctly identified, but } \\
\text { no diversity of aspects, so that questions of consis- } \\
\text { tency cannot arise. }\end{array}$ \\
\hline Multistructural & $\begin{array}{l}\text { Multiple relevant information presented and used, } \\
\text { but without considering relationships between dif- } \\
\text { ferent parts, so that inconsistency appears. }\end{array}$ \\
\hline Relational & $\begin{array}{l}\text { Multiple relevant information presented and used } \\
\text { in a way that recognizes relationships and achieves } \\
\text { consistency within the given task. }\end{array}$ \\
\hline Extended abstract & $\begin{array}{l}\text { Multiplicity recognized and consistency achieved } \\
\text { over a context beyond that of the given task. }\end{array}$ \\
\hline
\end{tabular}

validity of the argument, reflecting the SOLO division between Multistructural and Relational levels. Any solution containing a contradiction or evidence of misunderstanding of a concept is scored as at most 3, with scores from 1 to 3 distinguished by degrees of completeness. Logically consistent solutions are scored 5 when no errors are present, and 4 if there is a small error, like a slip in calculation. Examples of the scoring method are in Appendix A.

\subsection{Analysis and results}

\subsubsection{Comparison of means}

Scores on the 0-5 scale for individual tasks are compared using t-tests. In addition, a composite score out of 20 is constructed from the individual scores, weighted by the proportion of marks allocated to the questions on the original examination papers. Results are in Table 3.

All but two comparisons show that the scores for Cohort 2 are significantly higher than those for Cohort 1, and the two that do not give a significant 
Table 3: Results of comparisons of mean scores. Effect sizes are interpreted as in the work of Higgins and Katsipataki [10].

\begin{tabular}{|c|c|c|c|c|}
\hline $\begin{array}{l}\text { Group } \\
\text { Scores compared }\end{array}$ & $\begin{array}{l}\text { Cohort } 1 \\
n=301\end{array}$ & $\begin{array}{l}\text { Cohort } 2 \\
n=278\end{array}$ & $\mathrm{df}=577$ & Effect size \\
\hline \multicolumn{5}{|l|}{ Composite } \\
\hline Mean & 8.78 & 10.88 & $t=5.71^{a}$ & 0.48 \\
\hline Standard deviation & 4.74 & 4.04 & & (High) \\
\hline
\end{tabular}

Task 1: Complex nth roots

\begin{tabular}{l|llll} 
Mean & 2.11 & 2.55 & $\mathrm{t}=2.73^{\mathrm{b}}$ & 0.23 \\
Standard deviation & 2.01 & 1.89 & & (Moderate) \\
\hline
\end{tabular}

Task 2: Improper integrals

\begin{tabular}{l|llll} 
Mean & 1.79 & 2.05 & $\mathrm{t}=1.85^{\mathrm{c}}$ & 0.15 \\
Standard deviation & 1.81 & 1.54 & &
\end{tabular}

Task 3: Integration techniques

\begin{tabular}{l|llll} 
Mean & 3.10 & 3.40 & $t=1.83^{\mathrm{c}}$ & 0.15 \\
Standard deviation & 2.07 & 1.82 & &
\end{tabular}

Task 4: Lines in $\mathbb{R}^{3}$

\begin{tabular}{l|llll} 
Mean & 2.71 & 3.35 & $\mathrm{t}=3.64^{\mathrm{b}}$ & 0.30 \\
Standard deviation & 2.07 & 1.82 & & (Moderate) \\
\hline
\end{tabular}

Task 5: Linear equations

Mean

1.29

1.67

$\mathrm{t}=3.98^{\mathrm{a}}$

0.33

Standard deviation

$1.25 \quad 1.05$

(Moderate)

Task 6: Implicit differentiation

\begin{tabular}{l|llll} 
Mean & 3.73 & 4.17 & $t=3.13^{\mathrm{b}}$ & 0.26 \\
Standard deviation & 1.92 & 1.38 & & (Moderate) \\
\hline
\end{tabular}

Task 7: Mean value theorem

\begin{tabular}{l|llll} 
Mean & 1.65 & 2.72 & $t=8.41^{\mathrm{a}}$ & 0.70 \\
Standard deviation & 1.27 & 1.78 & & (Very High) \\
\hline
\end{tabular}

Task 8: Split function

\begin{tabular}{l|llll} 
Mean & 1.88 & 2.51 & $\mathrm{t}=4.78^{\mathrm{a}}$ & 0.40 \\
Standard deviation & 1.61 & 1.76 & & (Moderate)
\end{tabular}

${ }^{\mathrm{a}} \mathrm{p}<0.001 ; \quad{ }^{\mathrm{b}} \mathrm{p}<0.01 ; \quad{ }^{\mathrm{c}} \mathrm{p}<0.1$. 


\begin{tabular}{l|rrrrrr}
\multicolumn{7}{l}{ Table 4: Task 2-Improper integrals. } \\
\begin{tabular}{l|rrrrrr} 
Sample & 0 & 1 & 2 & 3 & 4 & 5 \\
\hline Cohort 1 frequencies & 136 & 8 & 19 & 88 & 20 & 30 \\
Cohort 2 frequencies & 87 & 13 & 10 & 148 & 6 & 15
\end{tabular}
\end{tabular}

result (Tasks 2 and 3) show Cohort 2 is slightly better than Cohort 1, with probability between 0.05 and 0.10 . Using the guide for interpreting effect sizes given by Higgins and Katsipataki [10], those for individual tasks mostly range from low to moderate, with one (Task 7 ) very high at 0.699 . The effect size for the composite score is 0.475 , which also qualifies as high, indicating that the significance of the test is not masking a trivial difference.

\subsubsection{Distributions of scores}

The actual frequency distributions of scores show a pattern of interest. For economy of space, only one example is given here, that for Task 2 (the improper integrals listed in Appendix A). Score frequencies are in Table 4.

Table 4 shows zero is the most common score among Cohort 1 students, and three is the most common score among Cohort 2 students. The pattern for the other tasks is similar for the most common scores, whereas top score frequencies show more variable patterns. The table for Task 2 was selected because it corresponds to a task where the difference between means, though close to reaching significance, did not achieve it. The common pattern in scores motivated examination of comparisons between distributions using chi-square tests, whose results are in Table 5.

The significant results of the chi-square tests support an argument that the common pattern of the distributions gives valid information about Cohort differences. That is, the pattern indicates that students in Cohort 2 were less likely to have very low scores than those in Cohort 1, so that they were more likely to be able to get started on each of the comparable tasks. This 


\begin{tabular}{l|rrrrrrrr} 
& Table 5: Differences between score distributions. & & \\
Task & 1 & 2 & 3 & 4 & 5 & 6 & 7 & 8 \\
\hline Chi-square & 17.42 & 42.51 & 11.31 & 66.82 & 48.50 & 17.42 & 85.55 & 167.89 \\
df & 5 & 5 & 5 & 5 & 5 & 5 & 5 & 4 \\
$p<$ & 0.001 & 0.010 & 0.05 & 0.001 & 0.001 & 0.001 & 0.001 & 0.001
\end{tabular}

suggests that those who needed help were getting more effective help from the program offered to Cohort 2.

\section{Discussion}

The comparisons between mean scores, consistently favouring the Cohort 2 sample, gave clear support to the reasoning underlying the change to more formative assessment. That is, formative practice opportunities, together with the assignment's requirements of attention to the structure of arguments and the presentation of evidence, were associated with better performance on the compared tasks. The assignment received a direct reward, and the practice opportunity promised a future reward, providing a motivational stimulus to participation in activities suited to the extension of understanding. The computer assisted feedback was also intended both to motivate persistence and to provide some degree of external scaffolding.

The comparisons between distributions of scores for the two Cohorts yielded additional information about subgroups in the two Cohorts. Over all tasks, the Cohort 2 sample distributions tended to contain lower frequencies for the lowest two scores and higher frequencies for the middle two, with no clear pattern for the top two. In addition, the differences were strong enough for the chi-square test results to be significant. A reasonable conclusion is that the benefit from the change in assessment was clear for the majority, but not traceable for the highest achievers.

Students in the mathematics subject studied here were in the first teaching period of their first year at university, so the results indicate that transition 
to university mathematics was easier for Cohort 2. It is possible that results for slightly later study periods could be different. A similar investigation dealing with students in their second mathematics subject is in progress.

The present study has examined only some observable written evidence about learning outcomes. The most obvious limitation of this type of study is that it does not include evidence about students' attitudes and their experience of studying. For example, extensive practice in problem solving could increase confidence about coping with mathematics. Without a naturally occurring quasi-experiment like the one that was investigated in the present work, group comparisons would not be possible, but students' perceptions of their learning situation would be worth examining, controlled by the digital audit trail of their use of the practice resource.

The underlying rationale for changing to more formative assessment was that feedback, together with attention to detail and the structure of mathematical arguments, should foster awareness of the processes of learning mathematics, and hence independence. It would be of interest to follow up the present examination of outcomes by direct investigation of students' perceptions of which assessment issues were salient or useful to them. Given that the present study found that effects of the assessment change seemed to be less marked among the most capable students, it would also be of interest to examine possible associations between students' achievement and their perceptions of the assessment methods. Initial qualitative research seems appropriate.

\section{References}

[1] S. Bengmark, H. Thunberg, and T. M. Winberg. "Success-factors in transition to university mathematics". In: Int. J. Math. Ed. Sci. Tech. 48.7 (2017), pp. 988-1001. DOI: 10.1080/0020739X.2017.1310311 (cit. on p. C258).

[2] J. B. Biggs and K. F. Collis. Evaluating the quality of learning: The SOLO taxonomy. Academic Press, New York, 1981. URL: 
https://www.elsevier.com/books/evaluating-the-quality-oflearning/biggs/978-0-12-097552-5 (cit. on p. C262).

[3] A. Bowen-James. Perceptions of learning environments among tertiary mathematics students. Sc.Ed.D. Thesis. Curtin University of Technology, 2002 (cit. on p. C262).

[4] H. Chick, J. M. Watson, and K. F. Collis. "Using the Solo taxonomy for error analysis in mathematics". In: Res. Math. Ed. Aust. 1.1 (1988), pp. 34-47 (cit. on p. C262).

[5] M. R. Freislich. A comparison between the effects of Keller Plan instruction and traditional teaching methods on the structure of learning outcomes among tertiary mathematics students. Sc.Ed.D. Thesis. Curtin University of Technology, 1997 (cit. on p. C262).

[6] M. R. Freislich. The effects of Keller Plan instruction on the achievement and attitudes of tertiary mathematics students. Proc. Int. Conf. Teach. Math., Istanbul. 2006 (cit. on p. C262).

[7] M. Gill and M. Greenow. "How effective is feedback in computer-aided assessment?" In: Learn. Media Tech. 33.3 (2008), pp. 207-220. DOI: 10.1080/17439880802324145 (cit. on p. C261).

[8] J. Hannah, A. James, and P. Williams. "Does computer-aided formative assessment improve learning outcomes?" In: Int. J. Math. Ed. Sci. Tech. 45.2 (2014), pp. 269-281. DOI: 10.1080/0020739X.2013.822583 (cit. on p. C261).

[9] D. Harris and M. Pampaka. "They [the lecturers] have to get through a certain amount in an hour': first year students' problems with service mathematics lectures". In: Teach. Math. App. 35.3 (2016), pp. 144-158. DOI: 10.1093/teamat/hrw013 (cit. on p. C258).

[10] S. Higgins and M. Katsipataki. "Communicating comparative findings from meta-analysis in educational research: some examples and suggestions". In: Int. J. Math.. Res. Meth. Ed. 39.3 (2016), pp. 237-254. DOI: 10.1080/1743727X.2016.1166486 (cit. on pp. C264, C265). 
[11] P. W. Hillock and R. N. Khan. "A support learning programme for first-year mathematics". In: Int. J. Math. Ed. Sci. Tech. 50.7 (2019), pp. 24-29. DOI: 10.1080/0020739X.2019.1656830 (cit. on p. C258).

[12] A. Hodge, J. C. Richardson, and C. S. York. "The impact of a web-based homework tool in university algebra courses on student learning and strategies". In: J. Online Learn. Teach. 5.4 (2009), pp. 618-629. URL:

https://jolt.merlot.org/vol5no4/hodge_1209.htm (cit. on p. C260).

[13] D. Holton and D. Clarke. "Scaffolding and metacognition". In: Int. J. Math. Ed. Sci. Tech. 37.2 (2006), pp. 127-143. DOI: $10.1080 / 00207390500285818$ (cit. on p. C259).

[14] A. H. Jonsdottir, A. Bjornsdottir, and G. Stefansson. "Difference in learning among students doing pen-and-paper homework compared to web-based homework in an introductory statistics course". In: J. Stat. Ed. 25.1 (2017), pp. 12-20. DOI: 10.1080/10691898.2017.1291289 (cit. on p. C259).

[15] M. McAlinden and A. Noyes. "Mathematics in the disciplines at the transition to university". In: Teach. Math. App. 38.2 (2019), pp. 61-73. DOI: 10.1093/teamat/hry004 (cit. on pp. C258, C259).

[16] J. Nicholas, L. Poladian, J. Mack, and R. Wilson. "Mathematics preparation for university: entry pathways and their effect on performance in first year mathematics and science subjects". In: Int. J. Innov. Sci. Math. Ed. 23.1 (2015), pp. 37-51. URL: https://openjournals. library.sydney.edu.au/index.php/CAL/ article/view/8488 (cit. on p. C258).

[17] M. I. Núñez-Peña, R. Bono, and M. Suárez-Pellicioni. "Feedback on students' performance: a possible way of reducing the negative effect of math anxiety in higher education". In: Int. J. Ed. Res. 70.1 (2015), pp. 80-87. DOI: 10.1016/j.ijer.2015.02.005 (cit. on p. C261). 
[18] J. T. E. Richardson. "Student learning in higher education: a commentary". In: Ed. Psych. Rev. 29.1 (2017), pp. 353-362. DOI: 10.1007/s10648-017-9410-x (cit. on p. C258).

[19] L. J. Rylands and D. Shearman. "Mathematics learning support and engagement in first year engineering". In: Int. J. Math. Ed. Sci. Tech. 49.8 (2018), pp. 1133-1147. DOI: 10.1080/0020739X.2018.1447699 (cit. on p. C258).

[20] K. A. Seaton. "Efficacy and efficiency in formative assessment: an informed reflection on the value of partial marking". In: Int. J. Math. Ed. Sci. Tech. 44.7 (2013), pp. 963-971. DOI: 10.1080/0020739X.2013.831490 (cit. on p. C260).

[21] D. Wood, J. S. Bruner, and G. Ross. "The role of tutoring in problem solving". In: J. Child Psychol. Psych. 17.1 (1976), pp. 89-100. DOI: 10.1111/j.1469-7610.1976.tb00381.x (cit. on p. C259).

[22] L. Zetterqvist. "Applied problems and use of technology in an aligned way in basic courses in probability and statistics for engineering students - a way to enhance understanding and increase motivation". In: Teach. Math. App. 36.2 (2017), pp. 108-122. DOI: 10.1093/teamat/hrx004 (cit. on p. C259).

\section{A Appendix: Scoring examples}

\section{A.1 Algebra}

\section{Task 1}

(a) Find all roots of $z^{5}=-1$.

(b) Factorise $z^{5}+1$ over the complex numbers.

(c) Factiorise $z^{5}+1$ over the real numbers. 
Table 6: Scores for algebra question.

Score

\begin{tabular}{ll}
\hline 5 & All correct \\
4 & Correct (a), (b), then $(\mathrm{c}) z^{5}+1=(z+1)\left[z^{2}-\right.$ \\
& $4 z \cos (\pi / 5)+1]\left[z^{2}-4 z \cos (3 \pi / 5)+1\right]$ \\
3 & Correct $(\mathrm{a}),(\mathrm{b})$, then $(\mathrm{c}) z^{5}+1=(z+1)\left(z-\mathrm{e}^{\mathrm{i} \pi / 5}\right)(z-$ \\
& $\left.\mathrm{e}^{\mathrm{i} \pi / 5}\right)\left(z-\mathrm{e}^{3 i \pi / 5}\right)\left(z-\mathrm{e}^{3 i \pi / 5}\right)$. \\
2 & Roots given as $e^{2 i k \pi}$, then corresponding form for $(\mathrm{b})$. \\
1 & $z^{5}=-1, z=\mathrm{e}^{2 i k \pi / 5}$, no more. \\
\hline
\end{tabular}

\section{Solution}

(a) Put $z=r e^{i t}$. Then $r^{5} e^{5 i t}=-1=e^{i \pi+2 i k \pi}$. So $r=1$ and $5 t=\pi+2 k \pi$ and the roots are $e^{i \pi / 5}, e^{-i \pi / 5}, e^{3 i \pi / 5}, e^{-3 i \pi / 5},-1$, for $k=-2,-1,0,1,2$.

(b) $z^{5}+1=(z+1)\left(z-e^{i \pi / 5}\right)\left(z-e^{-i \pi / 5}\right)\left(z-e^{3 i \pi / 5}\right)\left(z-e^{-3 i \pi / 5}\right)$.

(c) $z^{5}+1=(z+1)\left[z^{2}-2 z \cos (\pi / 5)+1\right]\left[z^{2}-2 z \cos (3 \pi / 5)+1\right]$.

Examples of scoring are described in Table 6.

\section{A.2 Calculus}

\section{Task 7}

(a) State the Mean Value Theorem.

(b) Use the theorem to prove $\sinh x>x$ for $x>0$.

\section{Solution}

(a) Mean Value Theorem: Let $f(x)$ be continuous on the interval $[a, b]$ and differentiable on $(a, b)$. The there exists $c$ in $(a, b)$ such that

$$
\frac{f(b)-f(a)}{b-a}=f^{\prime}(c) \text {. }
$$


Table 7: Scores for calculus question.

\begin{tabular}{ll}
\hline Score & \\
\hline 5 & All correct. \\
4 & Correct up to $(\sinh x) / x=\cosh c$, then a sketch show- \\
& ing $\cosh x>1$, but conclusion stated as following from \\
& $(\sinh x) / x>0$. \\
3 & Correct up to $(\sinh x) / x=\cosh c$, then "cosh $c<1$ so \\
& $\begin{array}{l}\text { Correct statement of the theorem, no more. } \\
2\end{array}$ \\
& Ratio formula for the theorem stated, no conditions, no \\
& more.
\end{tabular}

(b) $f(x)=\sinh x$ is continuous and differentiable everywhere, and $f^{\prime}(x)=$ $\cosh x$. So for $x>0$ there exists $c$ such that $0<c<x$ and $(\sinh x-$ $\sinh 0) /(x-0)=\cosh c$. Because $\cosh c>1$, we have $(\sinh x) / x>1$, and hence $\sinh x>x$.

Examples of scoring are described in Table 7.

\section{Author addresses}

1. M. R. Freislich, School of Mathematics and Statistics, University of New South Wales, NSW 2052, Australia.

mailto:m.freislich@unsw.edu.au orcid:0000-0002-3750-913X

2. A. Bowen-James, Le Cordon Bleu Australia Business School, Ryde, NSW 2112, Australia. 